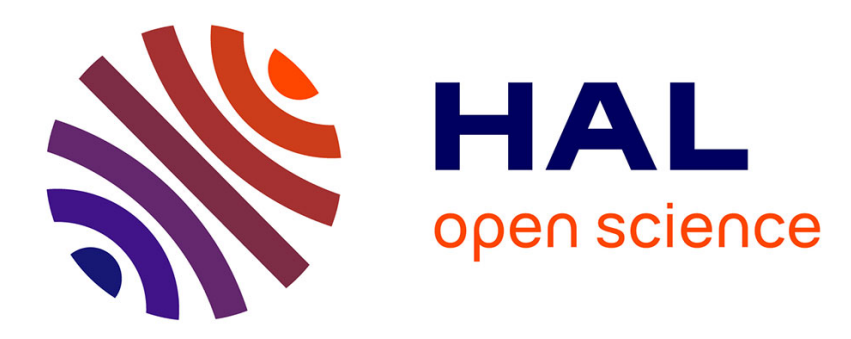

\title{
Fracturing of ice under compression creep as revealed by a multifractal analysis
}

\author{
Jérôme Weiss, Michel Gay
}

\section{To cite this version:}

Jérôme Weiss, Michel Gay. Fracturing of ice under compression creep as revealed by a multifractal analysis. Journal of Geophysical Research, 1998, 103, pp.24,005-24,016. 10.1029/98JB01758 . hal00645883

\section{HAL Id: hal-00645883 \\ https://hal.science/hal-00645883}

Submitted on 8 Feb 2021

HAL is a multi-disciplinary open access archive for the deposit and dissemination of scientific research documents, whether they are published or not. The documents may come from teaching and research institutions in France or abroad, or from public or private research centers.
L'archive ouverte pluridisciplinaire HAL, est destinée au dépôt et à la diffusion de documents scientifiques de niveau recherche, publiés ou non, émanant des établissements d'enseignement et de recherche français ou étrangers, des laboratoires publics ou privés. 


\title{
Fracturing of ice under compression creep as revealed by a multifractal analysis
}

\author{
Jérôme Weiss and Michel Gay \\ Laboratoire de Glaciologie et Géophysique de l'Environnement, UPR CNRS 5151, St Martin d'Hères, France
}

\begin{abstract}
Fracturing of freshwater granular ice up to failure under uniaxial compression creep was investigated from series of interrupted creep tests and from a multifractal analysis of the corresponding fracture patterns. At the early stages of damage corresponding to primary and secondary creep, the fracturing process is dominated by the nucleation of microcracks from stress concentrations within the material (unlike rocks, artificial freshwater ice does not contains starter flaws). Because of the crack nucleation mechanisms, the microstructure of the material (e.g., the nonfractal grain size distribution) strongly influences the organization of fracturing which is therefore nonfractal. As fracturing proceeds during tertiary creep, a hierarchical (fractal) organization of the fracturing emerges progressively over a wider scale range. At failure, this fractal organization is fully developed without detectable lower or upper bound, and the role of the initial microstructure has completely disappeared. Similarly, cracks are preferentially oriented along the compression axis at the early stages of damage, but this anisotropy vanishes as failure is approached. The simultaneity between the onset of tertiary creep and the emergence of fractal organization suggests that the acceleration of the deformation during tertiary creep is due to the cataclasis of a material which becomes granular. An important consequence of the fractal organization of fracturing is that homogenization procedures, as well as damage mechanics, developed to study the behavior of damaged materials, cannot be used to describe tertiary creep and failure.
\end{abstract}

\section{Introduction}

Offshore structures located in polar regions experience important forces when a moving sea-ice cover or icebergs crush against them. This problem has given rise, in the last 15 th years, to an abundant literature about damage, fracturing and failure of ice under compressive loading. The dependence of the compressive failure stress on temperature, strain rate or confinement has been established for different kinds of ice (see e.g. Schulson [1990] and Weiss and Schulson [1995] for granular ice or Schulson and Nickolayev [1995] for columnar saline ice). Note that iceberg ice (i.e. glacier ice) is granular, whereas sea ice is columnar. At high strain rates $\left(210^{-3} \mathrm{~s}^{-1}\right)$ and low confinement, the failure, which involves the evolution of very few cracks, has been successfully modeled at the laboratory scale [Schulson, 1990; Weiss and Schulson, 1995]. At lower strain rates $\left(10^{-7}-10^{-3} \mathrm{~s}^{-1}\right)$ and higher confinement, the situation is more complex: purely viscoplastic processes (dislocation creep [see Duval et al., 1983]) and damage mechanisms cooperate, and failure involves a large number of interacting fractures. This strain rate range is of particular practical importance since it corresponds to the conditions of ice/structure interaction encountered in arctic offshore engineering and to the situation where the compressive strength and so the forces on the structure are a maximum [Schulson, 1990]. In this regime, if the possible crack nucleation mechanisms have been identified [Frost, 1995], the further evolution of fracturing and the organization of

Copyright 1998 by the American Geophysical Union.

Paper number 98JB01758.

0148-0227/98/98JB-01758 $\$ 09.00$ fracture networks leading to failure have not yet been analyzed in detail. This constitutes one of the aims of the present work.

On the other hand, the fracturing processes of other geomaterials (i.e., essentially rocks) have been largely studied from the laboratory scale to the Earth's crust scale, and one major preoccupation was to relate large-scale features to small-scale (laboratory) observations. The self-similar nature of fracturing and faulting (i.e. the appearance of identical features at different scales) has been claimed both for laboratory experiments and field observations. This scale invariance can be expressed by power law distributions of fracture or fault lengths (see, e.g., Main [1996], Grasso and Bachelery [1995] or Cowie et al. [1995]) and by a fractal geometry of fracture networks (see, e.g., Davy et al. [1990] or Velde et al. [1993] for laboratory experiments and Turcotte [1992], Barton and Larsen [1985] or Ouillon et al. [1996a] for field observations). It has been recently recognized that a multifractal analysis is necessary to characterize completely the complexity of fracture or fault patterns [Ouillon et al.,1996a], and particularly their clustering properties. These clustering properties can be used as an indication of localization of damage and deformation.

Models of fracturing and fragmentation of rocks have been proposed which involve scale-invariant mechanisms of fracturing [Allègre et al., 1982; Turcotte, 1986] and lead to power law distributions and fractal geometry [see, e.g., Korvin, 1992]. King and Sammis [1992] argued that the fractal properties of rock fracturing result "naturally" from basic mechanical mechanisms such as crack nucleation from initial flaws, buckling of slabs, spalling, and interactions between particles of different sizes in a granular medium. However, they considered the evolution of damage and fracturing within materials which already contain a 


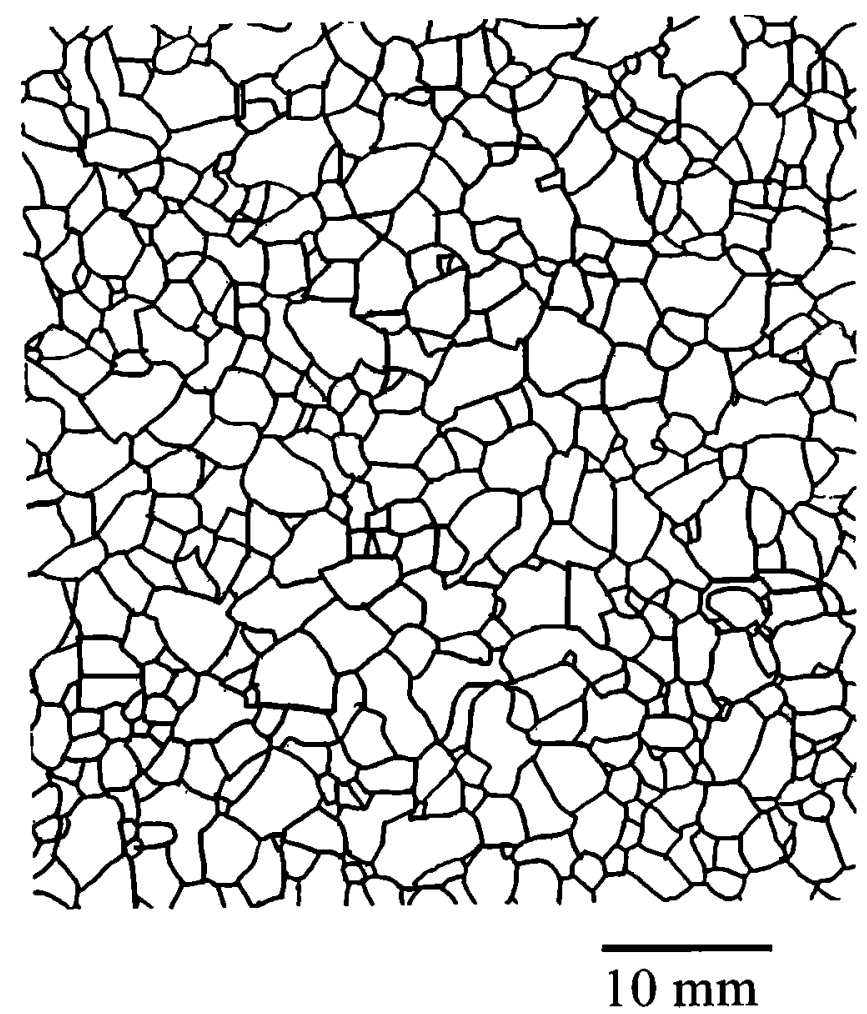

Figure 1a. Grain boundaries map of a typical sample of granular ice fractal distribution of initial defects. These defects act as starter defects for further fracturing. The importance of starter flaws on fracturing is usually supposed for rocks which contain microfractures, pores, and/or joints.

The aim of the present work was to follow step by step the fracturing of ice under compressive loading conditions (creep tests) where extensive viscoplastic deformation is associated with fracturing of the material. The complexity of the fracture patterns was analyzed with a multifractal formalism [Ouillon et al., 1996a] previously used to study rock fracturing. Within this context, we think that ice can be considered as a model material for the study of fracturing of other geomaterials like rocks, for three main reasons: (1) ice transparency and large grain sizes allow us to easily observe fracture patterns on thin sections of the damaged material, (2) the microstructure of the material (e.g., the grain size distribution) can be controlled during the elaboration of the material in the laboratory [Plé et al., 1996], and (3) unlike rock samples, artificial freshwater ice does not contain initial microfractures or pores. It is therefore interesting to follow the fracturing process of the material without making hypotheses on an initial distribution of flaws.

\section{Experimental Procedure}

Samples of freshwater granular ice with equiaxed, randomly oriented grains (so-called granular ice) were prepared from presieved fragments of ice, using a variation of the method described by Hallam et al. [1987]. A cylindrical mold was filled with presieved, calibrated ice particles. Then we added pure

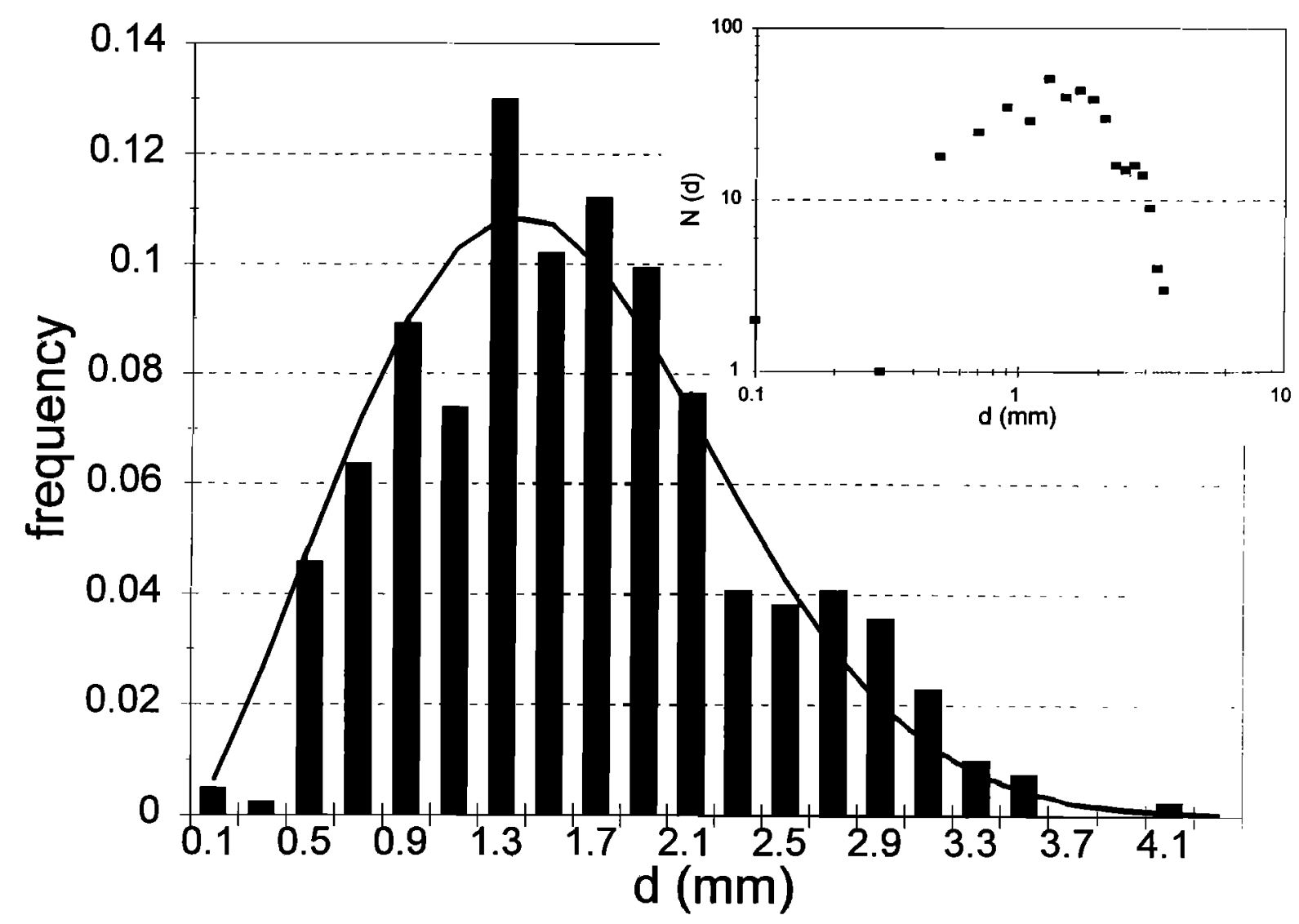

Figure 1b. Distribution of grain sizes of Figure 1a. This distribution can be fitted by a Weibull distribution, $f_{W}(d) \sim$ $\alpha \beta x^{a-1} \exp \left(-\beta x^{\alpha}\right)$, with $\alpha=2.30$ and $\beta=0.28$ (thin line). Insert shows the corresponding distribution in a log-log plot. $N(d)$, number of grain sizes between $d-0.1$ and $d+0.1 \mathrm{~mm}$ 


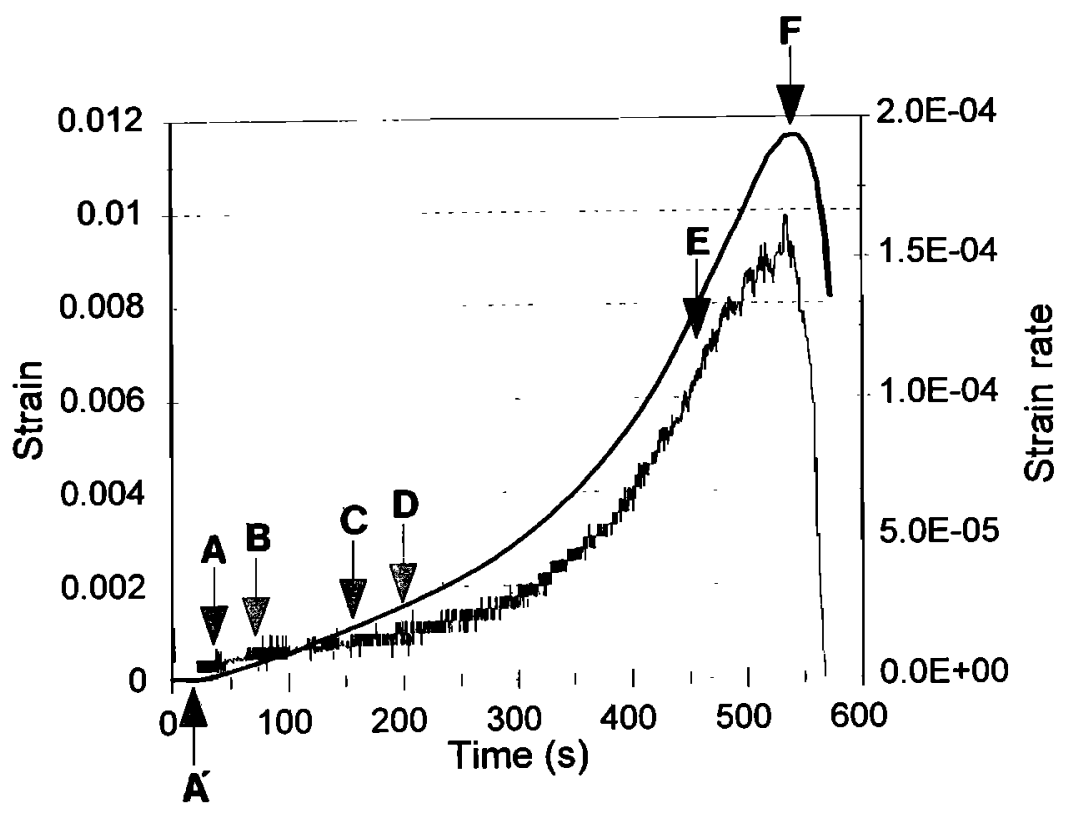

Figure 2. Axial strain (thick line) and axial strain rate (thin line) versus time for an uniaxial compression creep test on granular ice $\left(T=-10^{\circ} \mathrm{C} ; \sigma_{1}=3.1 \mathrm{MPa}\right)$. Arrows $\mathrm{A}^{\prime}$ to $\mathrm{E}$ correspond to the six interrupted tests. Arrow F corresponds to the failure of the sample.

distilled water at $0^{\circ} \mathrm{C}$ and pumped down to 0.1 torr to remove bubbles. The mold was then cooled from the bottom to freeze the mixture in about 24 hours. This allows partial control of the distribution of grain sizes. All the samples used in this work presented the same grain size distribution (Figures $1 \mathrm{a}$ and $1 \mathrm{~b}$ ) with a single maximum at $d \approx 1-1.5 \mathrm{~mm}$. This distribution can be reasonably well fitted by a Weibull distribution (see Figure $1 b$ ). This ice is an artificial model of natural iceberg ice. The grain size $d$ of a grain was determined from [Underwood, 1970]

$$
d=\pi \frac{A}{p}
$$

where $A$ and $p$ are the grain area and grain perimeter, respectively, measured from image analysis of thin sections of ice under cross polarizer. The insert in Figure lb shows the distribution in a log-log plot. Scale invariance is not observed: the microstructure of the material is not fractal.

Seven uniaxial compression creep tests (constant applied stress), interrupted at different stages of deformation, were performed at $-10^{\circ} \mathrm{C}$ with a compression stress of $3.1 \mathrm{MPa}$ on cylindrical samples ( $R \approx 35 \mathrm{~mm} ; L \approx 150 \mathrm{~mm}$ ). A typical strain-time curve of an experiment extended up to failure is represented on Figure 2. Figure 2 also shows at which points the other experiments were interrupted (before failure). Under such loading conditions, extensive viscoplastic deformation resulting from dislocation motion (dislocation creep [Duval et al., 1983]) is associated to the fracturing of the material. Qualitative and nondestructive observations of the sample during a test revealed that microcracking started after an axial strain of about $10^{-4}$, then densified within the entire sample throughout secondary and tertiary creep. Failure occurred on an highly damaged sample along a "shear fault" not well defined and with the ejection of fragments of different sizes.

After testing, transversal $\left(\left\llcorner\sigma_{1}\right)\right.$ and longitudinal $\left(/ / \sigma_{1}\right)$ thin sections (thickness of $2 \mathrm{~mm}$ ) of damaged ice were prepared and observed under transmitted natural light through a binocular microscope in order to reveal the fracture patterns. This gives twodimensional representations of the fracture networks with a resolution which can be estimated to be better than $0.1 \mathrm{~mm}$. This means that all fractures or branches longer than $0.1 \mathrm{~mm}$ have been mapped. The fracture patterns of five interrupted tests (A to $E$; noted by arrows on Figure 2) on transversal and longitudinal thin sections are represented on Figures 3 and 4, respectively. For a given stage, transversal and longitudinal sections were performed on the same sample. The maps of Figure 3 represent about $25 \%$ of the entire transversal section of the specimens, around the central axis. Note that this method of analysis of the fracturing is destructive: the different stages correspond to similar but different samples submitted to the same compression stress.

Before presenting a detailed analysis of these patterns, some general observations can be made:

1. After an axial strain of $7.2 \times 10^{-5}$ (stage $A^{\prime}$ on Figure 2), no fractures were visible on transversal nor on longitudinal thin section. Then fracture density, measured on the maps of Figures 3 and 4 as the cumulative length of fracture traces per square millimeter, increased regularly with axial deformation (Figure 5).

2. At the beginning of the damage process, i.e., stages A and B of Figures 3 and 4 , which correspond to secondary creep (see Figure 2), fractures are isolated. In other words, we are under the percolation threshold (here the word "percolation" is only used in its geometric meaning).

3. At stage $\mathrm{C}$, which corresponds to the beginning of tertiary creep, the fracturing pattern becomes more complex. We are close to the percolation threshold. The fracture network defines isolated "grains" on transversal as well as longitudinal planes. Then the network becomes denser, but no obvious localization process can be observed, even at stage $E$, close to failure.

4. At the same stage of damage, the fracture density is slightly, but systematically, lower on longitudinal thin sections than on transversal thin sections (Figure 5).

\section{Anisotropy of Fracture Patterns}

Owing to the uniaxial compression loading applied to the samples and the random orientation of the grains within granular ice, one expects an isotropy of fracture patterns observed on 

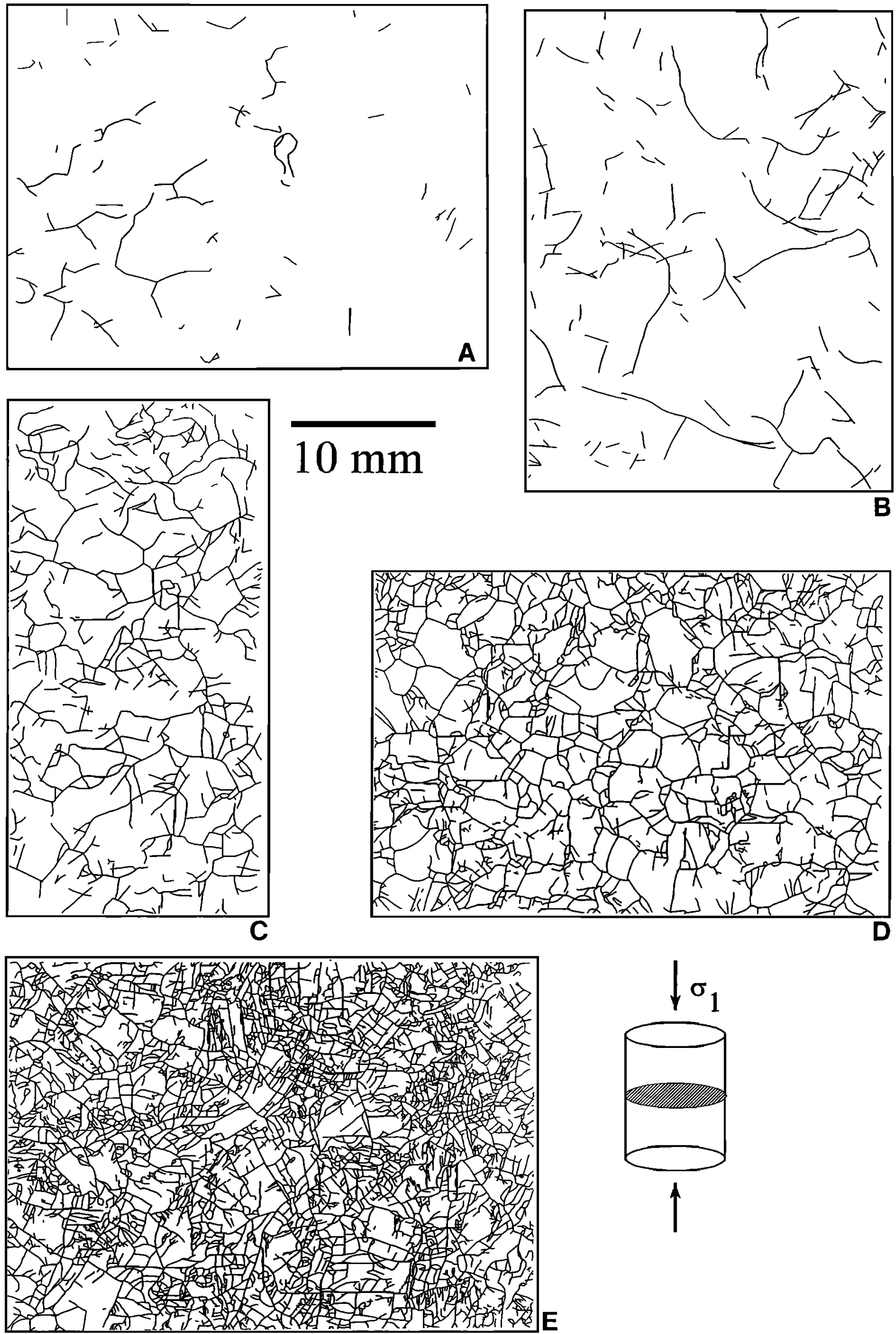

Figure 3. Fracture patterns on transversal sections of five successive interrupted compression creep tests, noted by arrows (A to E) on Figure $2\left(T=-10^{\circ} \mathrm{C} ; \sigma_{1}=3.1 \mathrm{MPa}\right)$. 

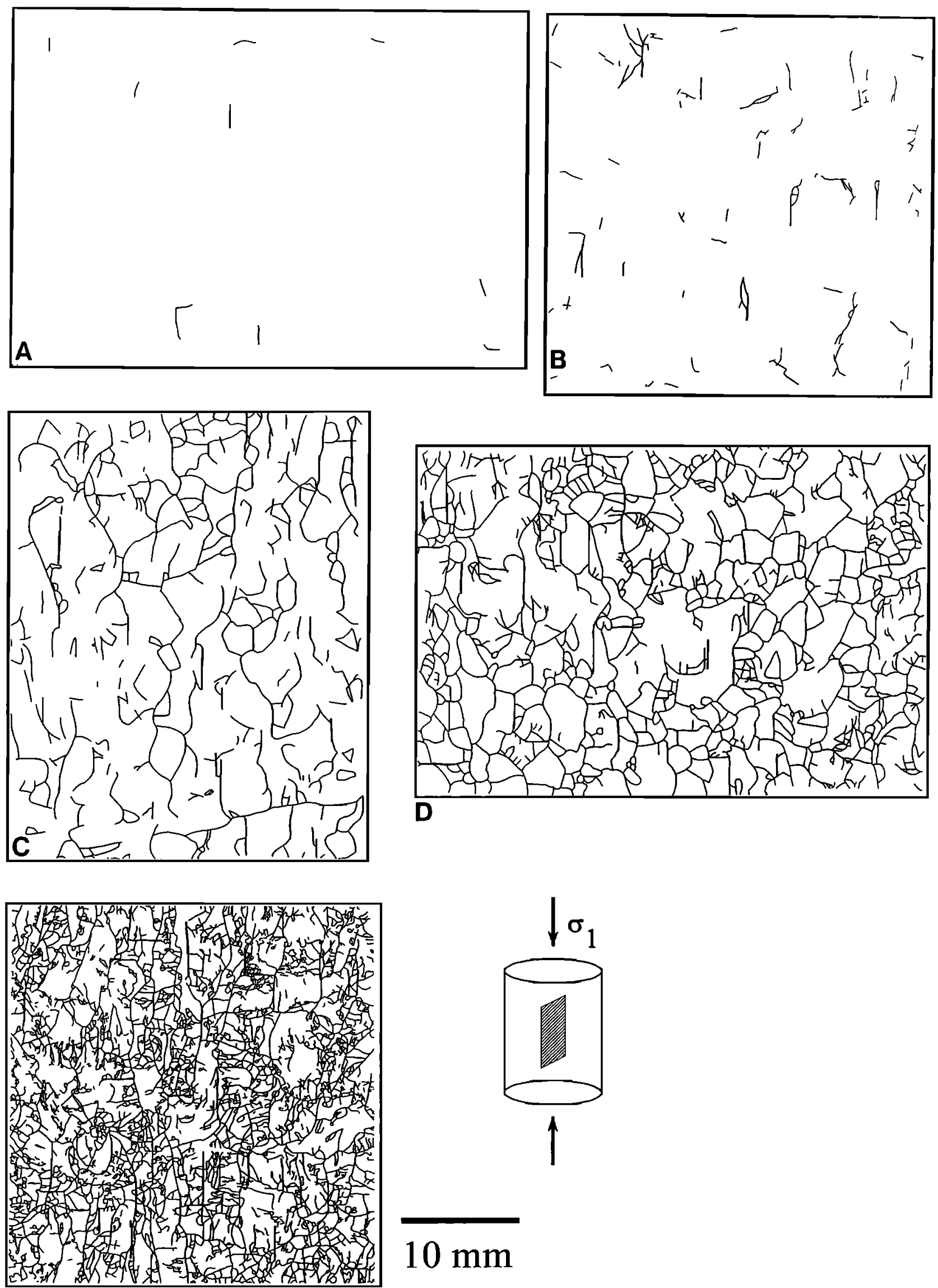

E

Figure 4. Fracture patterns on longitudinal sections of five successive interrupted compression creep tests, noted by arrows (A to $\mathrm{E}$ ) on Figure $2\left(\mathrm{~T}=-10^{\circ} \mathrm{C} ; \sigma_{1}=3.1 \mathrm{MPa}\right.$ ). 


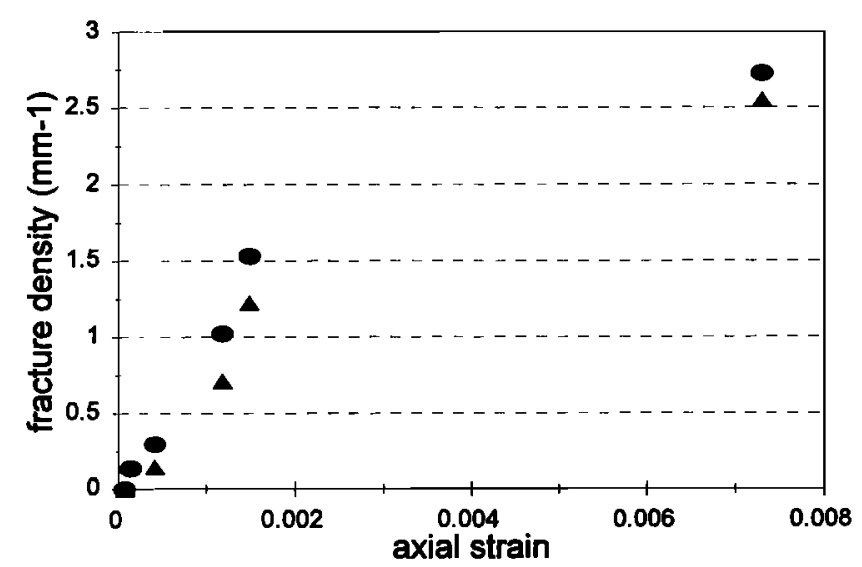

Figure 5. Fracture density (cumulated length per $\mathrm{mm}^{2}$ ) versus axial strain. Circles are transversal thin sections (Figure 3), and triangles are longitudinal thin sections (Figure 4).

transversal thin sections. On the other hand, if the fracturing process reflects the applied boundary conditions, an anisotropy of the patterns on longitudinal thin sections is expected. Models of initiation and propagation of individual fractures under compression and low confinement in an elastic medium predict fractures preferentially aligned along the maximum principal stress axis [Ashby and Hallam, 1986]. Whether or not this is verified when significant inelastic deformation occurs and when the fracture pattern becomes complex and percolated was checked during this work.

In order to evaluate quantitatively the level of anisotropy of a fracture network, each map of Figures 3 and 4 was covered by a grid of vertical and horizontal lines separated by $1 \mathrm{~mm}$. Then the number of intercepts with fractures, per unit length of test line, was calculated for vertical lines $\left(N_{V}\right)$ and horizontal lines $\left(N_{H}\right)$. The ratio $R$, defined as

$$
R=\frac{N_{V}}{N_{H}}
$$

characterizes the level of anisotropy of the network. $R=1$ for an isotropic pattern and tends toward 0 (or $+\infty$ ) for strongly anisotropic patterns. On transversal thin sections (Figure 3),

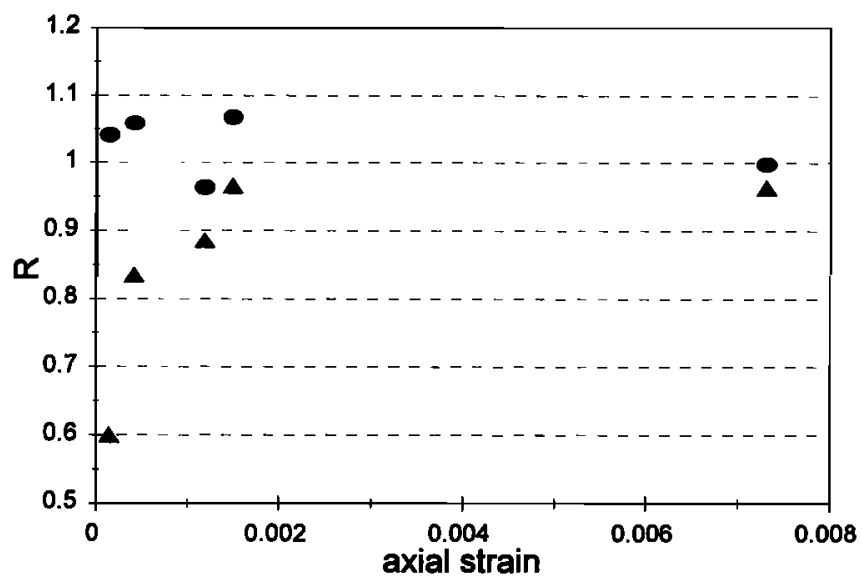

Figure 6. Evolution of the anisotropy of the fracture patterns (characterized by the ratio $R$; see text for more details) with axial strain. Circles are transversal thin sections (Figure 3), and triangles are longitudinal thin sections (Figure 4). horizontal and vertical axes were arbitrary. On longitudinal sections (Figure 4), the vertical axis was the compression axis. Therefore models developed for brittle solids [Ashby and Hallam, 1986] would predict small values of $R(<1)$ on longitudinal sections for uniaxial compression loading. The results obtained for the maps of Figures 3 and 4 are summarized on Figure 6. On transversal thin sections, $R$ is close to 1 whatever the axial strain. This is in agreement with the boundary conditions applied (uniaxial compression). On longitudinal thin sections, the fracture network is anisotropic at the early stages of damage, but this anisotropy decreases as fracturing proceeds. During tertiary creep (stages D and $E$ ), this anisotropy vanishes almost completely.

\section{Distribution of Fracture Lengths}

Power laws $N(L)-L^{-a}$ have been proposed to describe the distribution of fracture lengths in rocks, from a millimetric to a 100 kilometric scale [see, e.g., Main, 1996], where $N(L)$ is the number of fractures with a length greater than $L$. Such power law distributions have been presented as proofs of a fractal organization of the fracture process [Turcotte, 1992] and related to the physical mechanisms of fragmentation involving scale invariance [Turcotte, 1992]. Scale invariance is generally limited to a finite range, and the bounds, corresponding to breaks in slope of the power law distributions, can reveal internal characteristic scales or the size of the mechanical system [Grasso and Bachelery, 1995].

Figures $7 \mathrm{a}$ and $7 \mathrm{~b}$ represent the cumulative distributions of the lengths of fracture traces at stage $A$ on longitudinal and transversal
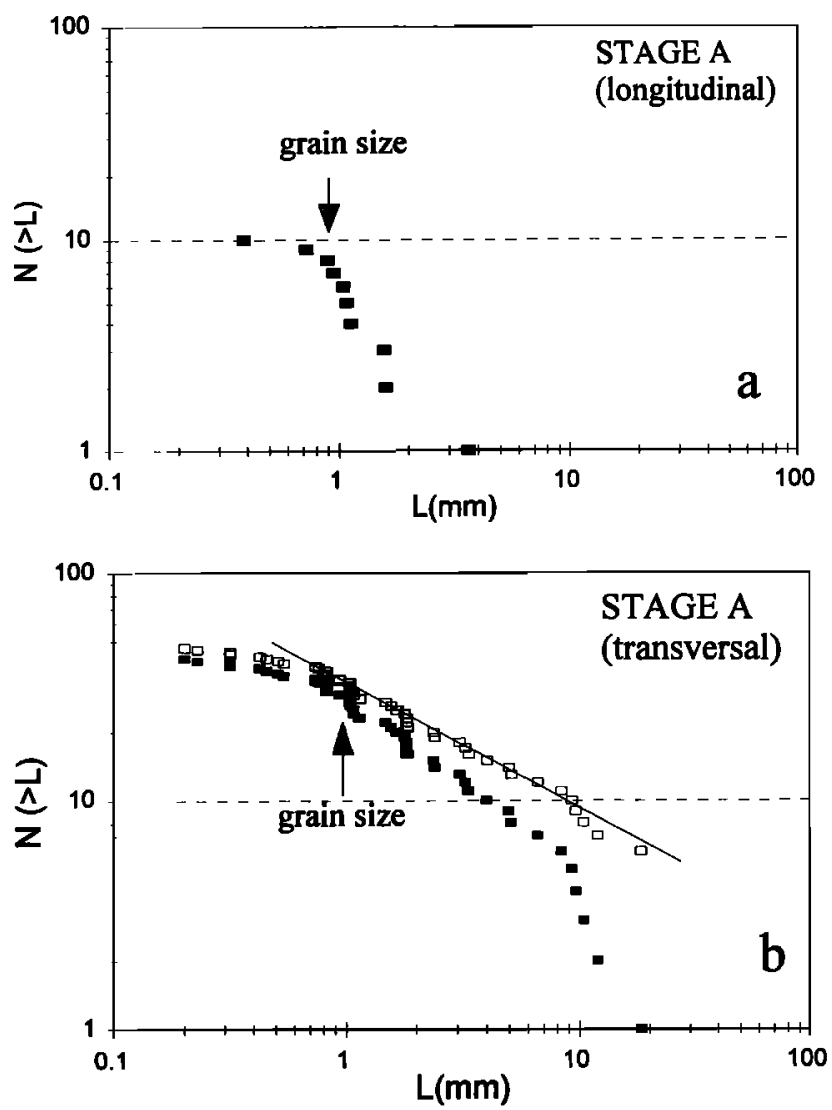

Figure 7. Cumulative distributions of fracture lengths at stage $A(a)$ on longitudinal thin section (Figure 4a) and (b) on transversal thin section (Figure 3a). Solid squares are uncorrected distribution and open squares are corrected distribution (see text for more details). 
thin sections, respectively. On Figure 7, "fractures" are defined as bounded clusters of fractures (using the vocabulary of percolation theory). At the onset of cracking, on longitudinal thin section (stage A, Figure 7a), despite the small number of fractures analyzed, it appears that all the fracture lengths are about $1 \mathrm{~mm}$, i.e., about or just below the mean grain size. At the same stage on transversal thin section, a power law distribution is observed on a limited scale range. Distributions similar to that of Figure $7 b$ are observed at stage $B$, both on longitudinal and transversal thin sections. These uncorrected cumulative distributions show a systematic deviation from power law at large scales. This is very likely due to a finitesampling effect [Pickering et al., 1995; Ouillon et al., 1996b]. This effect has been corrected, using the iterative procedure proposed by Pickering et al. [1995]. However, the corrected distributions (see Figure $7 \mathrm{~b}$ ) still show a lower bound to scale invariance at about 1 $\mathrm{mm}$, probably related to the unique internal scale of the microstructure, i.e., the mean grain size. Very few cracks are smaller than the mean grain size.

Unlike rocks, artificially grown ice samples do not initially contain internal microfractures. In the early stages of the damage process under compression, microcrack nucleation occurs from tensile stress concentrations. Whatever the physical mechanisms invoked (elastic anisotropy; grain boundary sliding, or dislocation pile-up), they predict microcrack lengths of the order of the grain size [see, e.g., Frost, 1995]. Therefore the first stage of cracking corresponds to a nucleation stage with fracture lengths scaling with the mean grain size. This way, one can easily explain the distribution of microcrack sizes at stage $A$ on longitudinal section (Figure 7a). In agreement with the present work, Cole [1986] found a tight relationship between the average microcrack size and the average grain size during the early stages of damage of granular ice under uniaxial compression creep at $-5^{\circ} \mathrm{C}$. At stage $A$ on transversal thin section (Figure 7b), as well as at stage $B$ on longitudinal and transversal thin sections, a scale invariance seems to emerge above the mean grain size. The slope $a$ of the corrected power law distributions is equal to 1 for longitudinal section at stage $B$ and to 0.53 for transversal sections at stages A and B (Figure 7b). These values are similar to those reported by Main [1996] from a compilation of laboratory and field data $(a \approx 1)$ and by Grasso and Bachelery [1995] for fissure length distributions on the Piton de la Fournaise volcano $(a \approx 0.6-0.7)$. The difference in the distributions observed at stage $A$ between longitudinal and transversal thin sections could suggest that the evolution of fracturing is, to some extent, "delayed" when observed along the principal stress axis, in agreement with the slight anisotropy of damage reported above.

This analysis of fracture length distributions indicates that the early stages of fracturing are influenced by the initial microstructure (grain size). The organization of fracturing is therefore nonfractal, although scale invariance seems to emerge progressively.

Complex fracture networks, above the percolation threshold (Figures $3 \mathrm{c}$ to $3 \mathrm{e}$ and $4 \mathrm{c}$ to $4 \mathrm{e}$ ) cannot be analyzed in terms of fracture length distributions because fractures are no longer isolated. Others tools are needed to describe this increasing complexity and to confirm or infirm scale invariance of the fracturing process.

\section{Multifractal Analysis of Fracture Patterns}

It has been argued that fracture or fault patterns observed in nature [see, e.g., Korvin, 1992] or in laboratory experiments [Davy et al., 1990; Velde et al., 1993] have a fractal geometry, characterized by a fractal dimension $D$, at least within a certain range of scales. However, a monofractal analysis gives no information on the way the fracture density is spatially distributed, homogeneously or heterogeneously. A multifractal analysis [Hentschel and Procaccia, 1983] is necessary to characterize completely the self-similar properties of objects or measures, including the spatial variability and clustering properties. Ouillon et al. [1996a] showed that natural fracturing of the Arabian plate is uniform at small scales $(<6 \mathrm{~km})$ and multifractal at larger scales. The multifractal analysis was used to reveal this characteristic scale.

On the maps of Figures 3 and 4, we performed a multifractal analysis of the fracture networks similar to that performed by Ouillon et al. [1996a], in order (1) to check the self-similar properties of the patterns (if any), (2) if the fracture networks are self-similar (fractal) within a certain scale range, to reveal the associated bounds, and (3) to quantify the degree of concentration and the clustering properties of the patterns; in other words, to try to follow a localization of damage as approaching failure of the samples. The analysis was performed using the standard boxcounting method which consists in covering a map by a regular array of boxes of side $l$. A measure $p_{l}(l)$ is attached to each nonempty box $i$ and defined as the proportion of fracture length contained in the box (see Ouillon and Sornette [1996] for more details). Then, the moments of order $q$ of the measure are calculated from:

$$
M_{q}(l)=\sum_{i=1}^{n(l)} p_{i}^{q}(l)
$$

where $n(l)$ is the number of non-empty boxes. For self-similar measures, $M_{q}(l)$ scales as

$$
M_{q}(l) \sim l^{(q-1) D_{q}}
$$

This defines the set of generalized fractal dimensions $D_{q}$ which characterize the self-similar properties of the fractal object or measure. It has been shown [Hentschel and Procaccia, 1983] that $D_{0}, D_{t}$ and $D_{2}$ so defined correspond respectively to the capacity, information, and correlation dimensions. Note that $M_{0}(l)$ is simply the number of nonempty boxes of size $l$ needed to cover the network and $D_{l}$ (information dimension) is defined as the proportionality coefficient between $\sum, p, \log \left(p_{\nu}\right)$ and $\log (l)$ :

$$
\sum_{l=1}^{n(l)} p_{i} \log \left(p_{l}\right) \sim D_{1} \log (l)
$$

but it has been shown that $D_{q} \rightarrow D_{1}$ as $q \rightarrow 1$. As $q$ increases, the moments $M_{q}$ are controlled by the most densely filled boxes, and the dimensions $D_{q}$ provide information about the most clustered properties of the fractal set [Lei et al., 1993; Ouillon et al., 1996a]. The special case $D_{0}=D_{l}=D_{q}$ characterizes a monofractal, whereas an increasing difference between $D_{0}$ and $D_{q>1}$ reveals a multifractal and an increasingly clustered measure. This will be used in this work to quantify the degree of localization during the fracturing process (see below). In what follows, we will limit our analysis to the calculation of the fractal dimensions $D_{0}$ to $D_{6}$. The difference $D_{0}-D_{6}$ will be used as an estimate of the degree of localization.

The possible bias from an irregular border geometry [Ouillon et al., 1996a; Ouillon and Sornette, 1996] was avoided in our measurements by the use of rectangular maps, exactly covered by the sets of squares boxes. On the other hand, bias due to finite sampling was more difficult to evaluate and could be especially significant for stages A or B with low fracture densities. To check this, at each stage we performed a multifractal analysis on a square map included in the initial map and representing about $15 \%$ of the initial surface. The finite-sampling bias, if any, should be larger for these reduced maps. The analyses on the small maps gave the same results as the initial maps (same dimensions; same bounds). This suggests that the bias was small. Working on unbiased synthetic fracture patterns, Ouillon et al. [1996a] found a lower bound for the 

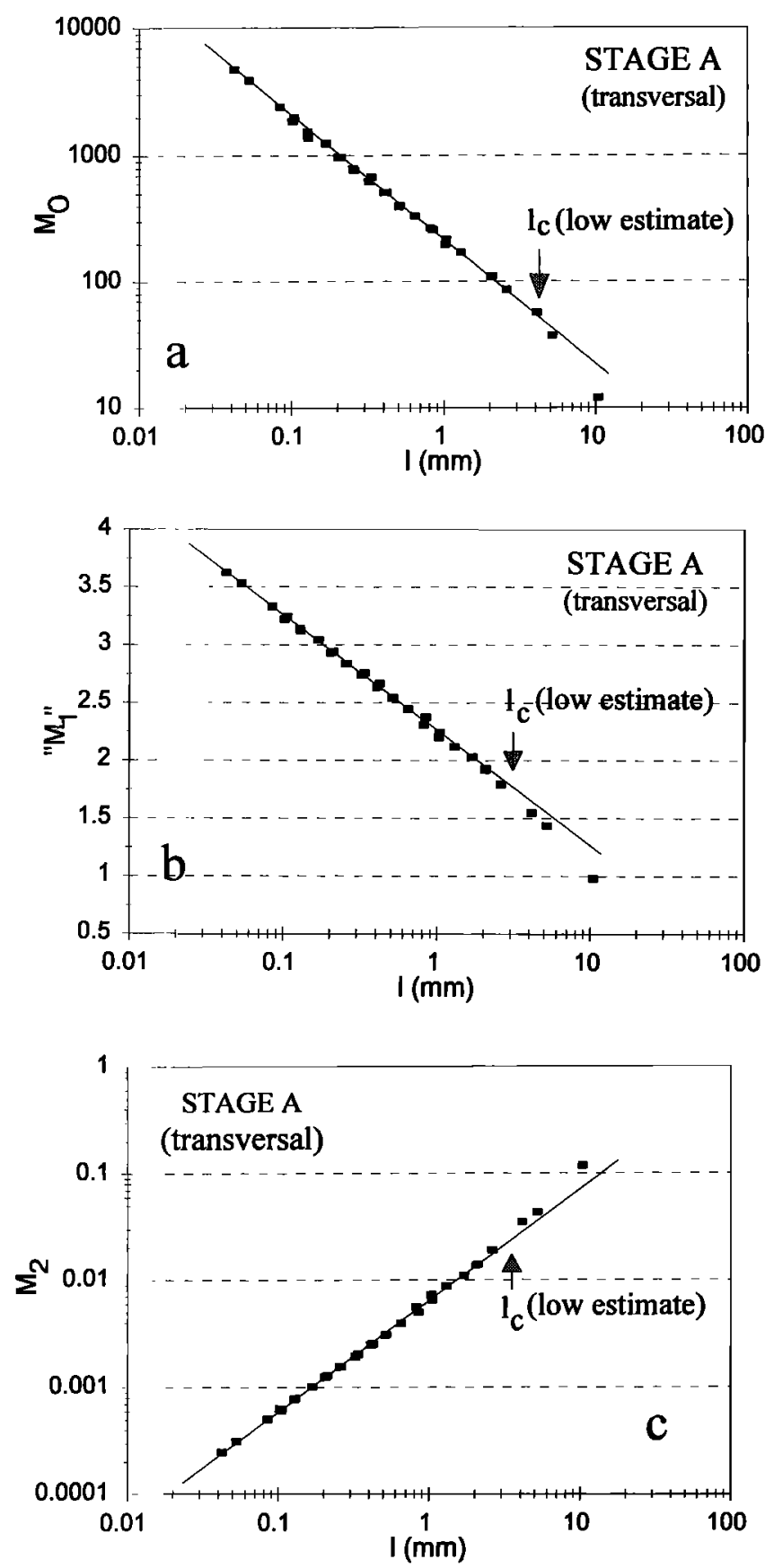

Figure 8. Multifractal analysis of the fracture pattern of stage $A$ (transversal thin section; Figure 3a).(a) $M_{0}$ (number of nonempty boxes) versus box size $l$, (b) $\sum_{1} p_{l} \log \left(p_{\nu}\right)\left(" M_{l}\right.$ ") versus box size $l$, and (c) $M_{2}$ versus box size $l$.The slopes of the three diagrams give $D_{0}=D_{1}=D_{2}=1 \pm 0.05$

uncertainty on the estimation of generalized fractal dimensions of about 0.05 .

Figures $8 \mathrm{a}$ to $8 \mathrm{c}$ represent the relationships between $M_{0}(l), \Sigma_{\text {, }}$ $p_{i} \log \left(p_{\nu}\right)\left(" M_{\Lambda}(l)\right)$ and $M_{2}(l)$, respectively, and the boxes' size $l$, for the fracture network of stage $A$ on transversal thin section (Figure 3a). A linear behavior is observed up to a box size $l$ of about 2-4 $\mathrm{mm}$. A deviation from linearity is observed above. The dimensions $D_{0}$ to $D_{6}$ calculated on the linear part are all equal to $1 \pm 0.05$. This situation is unchanged at stage $B$ and on longitudinal section (stages $\mathrm{A}$ and $\mathrm{B}$; graphs not represented). $D_{q}=1$ simply means that within the scale range of observation, the traces of the cracks are regular, nonfractal. This does not give information about the spatial distribution of the fractures. Such information would be only available when observing larger maps at larger scales, probably above the deviation observed around $4 \mathrm{~mm}$.

Starting from stage $C$, at the beginning of tertiary creep, the situation seems to change (see Figures $9 \mathrm{a}$ to $9 \mathrm{c}$ for transversal thin section). At small scales, the $D_{q}$ are equal to $1 \pm 0.1$, as previously observed for stages A and B (see above). Within an intermediate, narrow scale range ( $\sim$ 0.8-1.3 mm on Figures 9 a to $9 \mathrm{c})$, a transition
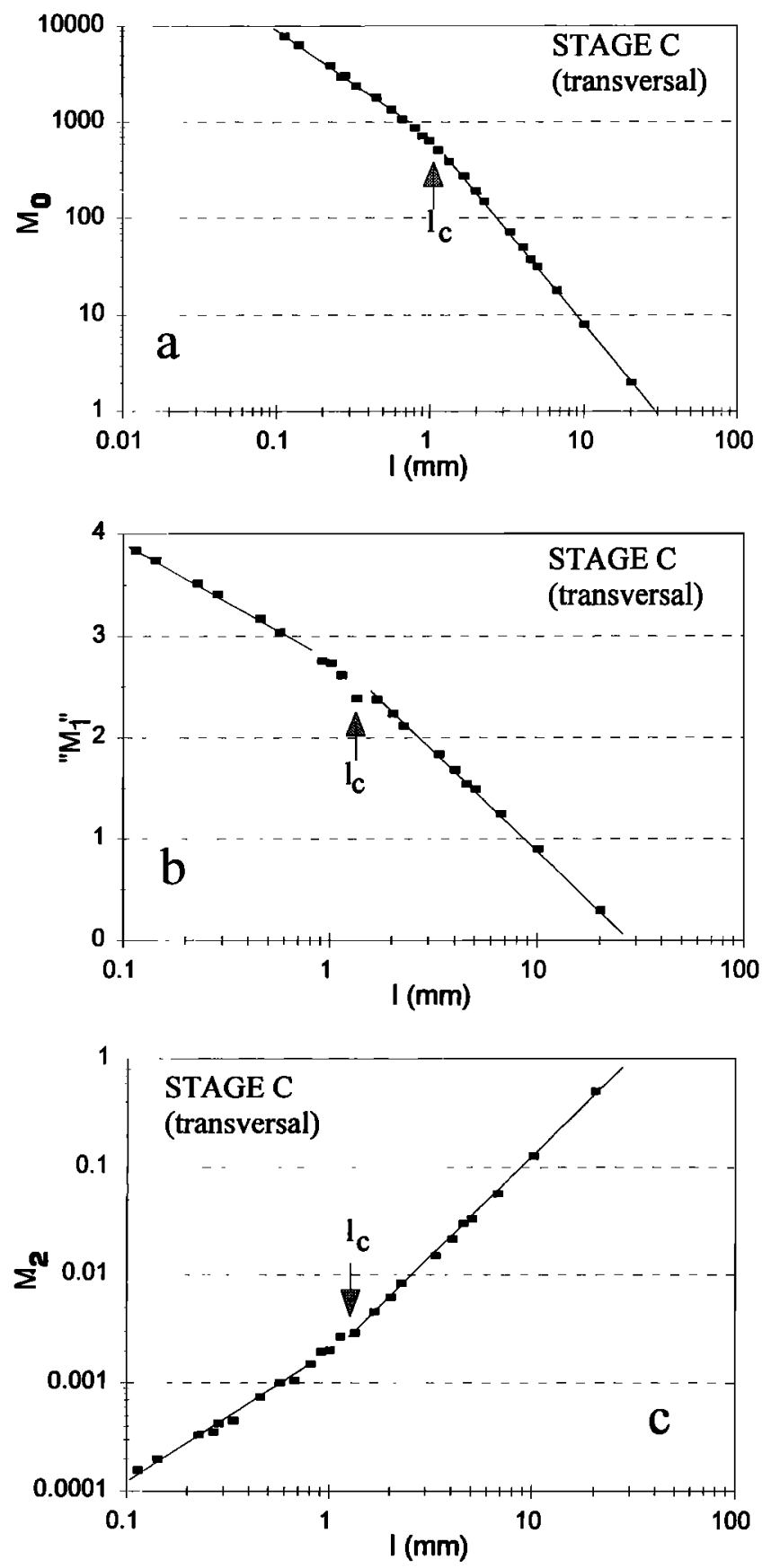

Figure 9. Multifractal analysis of the fracture pattern of stage $\mathrm{C}$ (transversal thin section; Figure 3c).(a) $M_{0}$ (number of nonempty boxes) versus box size $l$, (b) $\sum_{l} p_{i} \log \left(p_{l}\right)\left(" M_{l}\right.$ ") versus box size $l$, and (c) $M_{2}$ versus box size $l$.The fracture pattern is multifractal $\left(D_{0}>D_{l}>D_{2}>D_{q>2} \neq 1\right)$ above the threshold scale $l_{c}=1.3 \mathrm{~mm}$. 
Table 1. Generalized Fractal Dimensions for Scales Larger Than $l_{c}$

\begin{tabular}{llllllllll}
\hline STAGE & Type & $\mathrm{D}_{i 1}$ & $\mathrm{D}_{1}$ & $\mathrm{D}_{2}$ & $\mathrm{D}_{3}$ & $\mathrm{D}_{4}$ & $\mathrm{D}_{5}$ & $\mathrm{D}_{6}$ & $\mathrm{D}_{0}-\mathrm{D}_{6}$ \\
\hline \multirow{2}{*}{$\mathrm{C}$} & Trans. & 199 & 1.95 & 192 & 1.89 & 1.88 & 1.86 & 1.85 & 0.14 \\
& Longit & 1.97 & 1.85 & 1.79 & 1.75 & 1.72 & 1.70 & 1.69 & 0.28 \\
& Trans. & 1.99 & 1.94 & 1.91 & 1.89 & 1.87 & 1.86 & 1.84 & 0.15 \\
$\mathrm{D}$ & Longit & 1.87 & 1.77 & 1.73 & 1.70 & 168 & 166 & 164 & 023 \\
& Trans. & 2.00 & 1.97 & 1.95 & 1.93 & 1.92 & 1.91 & 1.90 & 0.10 \\
$\mathrm{E}$ & Longit & 2.00 & 1.98 & 1.96 & 1.95 & 193 & 1.92 & 1.91 & 009 \\
\hline
\end{tabular}

Trans., transversal thin section, and Longit , longitudinal thin section.

behavior is observed. Above a critical scale $l_{c}(1.3 \mathrm{~mm}$ on Figures $9 \mathrm{a}$ to $9 \mathrm{c}$ ), a fractal fracture pattern is observed, i.e., $M_{q}$ scale as $l^{(q-1) D q}$ with $D_{q} \neq 1$. Only this "large-scale" regime gives information about the structure of the network. Note that $l_{c}$ is defined here as the lower bound for scale invariance, i.e., the boundary between the intermediate- and the large-scale regimes. For a given stage, the value of $l_{c}$ is the same whatever $q$. Similar results are observed for stages $\mathrm{D}$ and $\mathrm{E}$ as well as on longitudinal thin sections at stages $\mathrm{C}$, $\mathrm{D}$, and $\mathrm{E}$ (graphs not represented). The dimensions $D_{0}$ to $D_{6}$ calculated on transversal as well as longitudinal thin sections, for stages C, D, and E, are summarized on Table 1. Very similar spectrums of fractal dimensions $D_{q}$ are observed for stages C, D, and $\mathrm{E}$, on transversal thin sections. The slow decrease of $D_{q}$ with $q$ indicates that fracture networks are slightly multifractal and the values of $D_{0}$, close to 2 , show that the fracture networks are close to be dense in the plane. The very slight differences observed for $D_{0}-D_{6}$ at different stages of deformation do not reveal an increasing clustering of damage as fracturing proceeds. These differences are below the lower bound of uncertainty for the calculation of the dimensions (0.05 [Ouillon et al., 1996a]). On the other hand, an important difference exist between the stages $C, D$, and $E$ : the critical scale $l_{c}$ is decreasing with increasing axial strain, as fracturing proceeds (Figure 10). Since $l_{c}$ is decreasing as fracturing

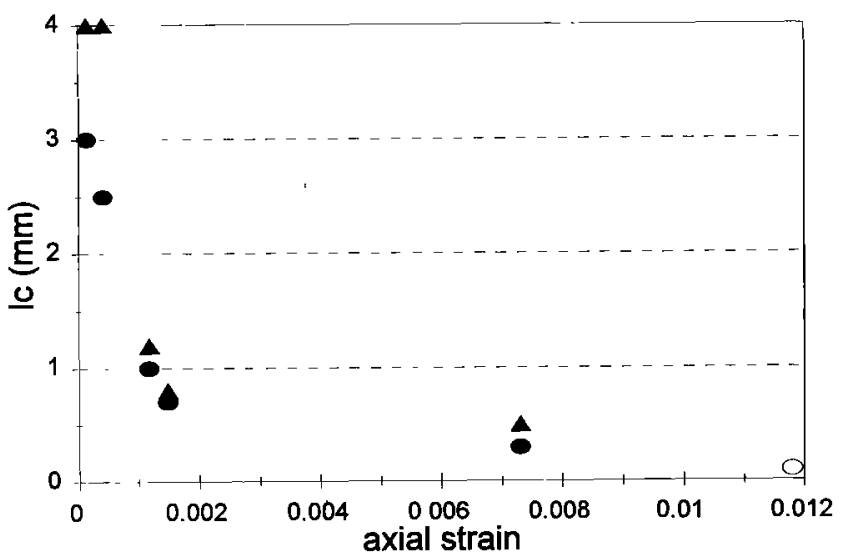

Figure 10. Evolution of the threshold scale $l_{c}$ with the axial strain. The solid circles are determined from the multifractal analysis of transversal thin sections. The solid triangles are determined from the multifractal analysis of longitudinal thin sections. For stages $A$ and $\mathrm{B}$ the given values of $l_{c}$ are low estimates (see text for details). The open circle corresponds to an upper bound for $l_{c}$ determined from the distribution of fragment sizes at failure (see Figure 11). proceeds, this lower bound to scale invariance cannot be related to the resolution limit of the analysis, which is unchanged for the different levels of damage. The multifractal analysis performed on the longitudinal thin sections of the Figure 4 led to a similar conclusion. Compared with the transversal thin sections, the fractal dimensions are very similar (Table 1), although the multifractal character seems slightly more pronounced at stages $\mathrm{C}$ and $\mathrm{D}$. One other difference appears: the critical length $l_{c}$ is slightly larger on the longitudinal plane than on the transversal plane (see Figure 10). Once again, the evolution of fracturing seems delayed on the longitudinal plane compared to the transversal plane.

Finally, coming back to stages $\mathrm{A}$ and $\mathrm{B}$, one can suspect the deviation observed at large scales to be actually the intermediate, transition regime toward a large-scale regime. This last regime is inaccessible at these stages within the scale range explored. However, the deviation from linearity gives a low estimate for $l_{c}$, which is significantly larger at these early stages of fracturing than later on (Figure 10).

\section{Discussion and conclusions}

The scenario of the fracturing process of ice under compression creep can now be reconstituted.

Before loading, the initial material does not contain internal flaws, like microfractures, pores, or joints. Upon loading, the elastic and plastic anisotropy of the grains generates strain incompatibilities between neighboring grains of different crystallographic orientations. Consequently, internal stress concentrations develop within the ice (see Weiss et al., [1996] for elastic anisotropy and Duval et al., [1983] for plastic anisotropy) and are responsible for microcrack nucleation. Within the strain rate range of interest for the present work, the role of the plastic anisotropy prevails. In granular ice with randomly oriented grains, the peaks of the internal stress field are uniformly distributed and not clustered. One can therefore expect a uniform spatial distribution of microfractures at these early stages of deformation, corresponding to primary and secondary creep. Unfortunately, it was impossible to check this precisely at scales larger than $10 \mathrm{~mm}$ (see above). On the other hand, it was shown that fracture traces were regular $\left(D_{q}=1\right)$, in agreement with independent nucleations events and therefore fractures shapes weakly influenced by the others fractures. The initial microstructure imposes a nonfractal fracture pattern (see Figure 7a) with a characteristic scale corresponding to the mean grain size. However, as fracturing proceeds during secondary creep, a hierarchical organization emerges progressively, as revealed by the distributions of fracture lengths (Figure $7 b$ ). This underlying organization suggests that fractures start to interact between each other through their 
associated stress fields. Before the onset of tertiary creep, this organization is limited to a small-scale range with a lower bound corresponding to the mean grain size. At this stage, the initial microstructure still governs largely the fracturing process. On the other hand, at these early stages of damage, fracture patterns are slightly anisotropic (Figure 6). Fractures are preferentially oriented along the compression axis. This indicates that the nucleation and the early stages of propagation of the fractures are also partly influenced by the remote uniaxial stress field.

The fracture network percolates at the onset of tertiary creep. Strictly speaking, at stage $C$, we observed a percolation of the traces of the fractures on a plane, both on transversal (Figure 3c) and longitudinal (Figure 4c) thin sections. The 3d percolation occurred before, between stages B and C. As stated previously, starting from stage $C$, the fracture networks define isolated "grains" on transversal as well as longitudinal planes. This suggests that some isolated fragments are already present within the damaged material. However, a rigorous stereological analysis is here impossible to perform to reconstitute the $3 \mathrm{~d}$ network from $2 \mathrm{~d}$ images, without making several simplifying hypotheses [Underwood, 1970]. The reconstitution of 3d fracture networks would need the realization of a series of parallel thin sections. From stage C, the multifractal analysis reveals a multifractal fracture pattern above a critical scale $l_{c}$. This fractal self-organization of the fracturing indicates that fractures interact between each other. The small degree of multifractality shows that fractures are slightly clustered. This situation does not change significantly up to stage $E$, and so one cannot detect an increase of the localization of damage up to this stage. Because of the very high level of fracturing, it was impossible to analyze thin sections of damaged ice after stage $\mathrm{E}$. Axial strain at stage $\mathrm{E}$ represents more than $60 \%$ of the strain at failure. The multifractal analysis presented shows that the localization into a "shear fault" occurs later than $60 \%$ of the failure strain. It is interesting to compare the present results to those presented by Hirata et al. [1987] from acoustic emission (AE) measurements. They calculated the correlation dimension $D_{2}$ of the $\mathrm{AE}$ hypocenters during a compressive creep test on granite with confining pressure and found a significant decrease of $D_{2}$ from 2.75 in primary creep to 2.25 in tertiary creep, arguing for a progressive localization of damage as approaching failure. The present multifractal analysis of fracture patterns carried out during compression creep of ice did not revealed any significant localization up to an advanced stage of tertiary creep. Whether this difference is due to a different evaluation of the fracturing ( $\mathrm{AE}$ versus direct observation), different material properties, the confining pressure applied during Hirata et al.'s experiments, or the absence of starters flaws in ice remains a question.

At the onset of tertiary creep, the scale invariance of the fracture network ceases below a lower bound $l_{c}$ of about $1.3 \mathrm{~mm}$ (i.e., the mean grain size). The initial microstructure still influences the fracturing process. It is worth noting here that Kusunose et al. [1991] observed similar grain size effects on the fractal structure of AE hypocenters during constant loading rate compression of granites. As shown on Figure 10, $l_{c}$ decreases as fracturing proceeds, which means that the fractal organization of the fracturing spreads over a larger scale range (toward the small scales). As noted above, thin section analyses were impossible to carry out after stage E. However, on a test loaded up to failure, we collected all the ice fragments after testing, except the two main blocks on each part of the fault, and we determined their size distribution by successive sieving. This distribution is represented on Figure 11. A power law distribution is observed on the full scale range ( 3 orders of magnitude) without detectable lower bound above the resolution limit of $0.1 \mathrm{~mm}$. Therefore, at failure, the fracturing is fully self-organized, without characteristic length, and the role of the initial microstructure has completely disappeared.

This scenario is valid for transversal as well as longitudinal planes. However, the evolution of fracturing seems delayed along a longitudinal plane compared to a transversal plane. Moreover, the slight anisotropy observed at the early stages of deformation decreased as fracturing proceeds and vanishes during tertiary creep. The fragmentation of the material appears as isotropic, despite the anisotropic boundary conditions applied.

From this general scenario, the following main conclusions can be drawn. A hierarchical (fractal) organization develops during fracturing of granular ice under compression creep. This organization emerges from an initial nonfractal situation imposed by the microstructure of the material. It is therefore not necessary to presuppose a fractal distribution of internal starter flaws to explain the hierarchical organization of the fracturing in geomaterials like rocks. This is in agreement with the numerical modeling of Cowie et al. [1995], who concluded that a preexisting

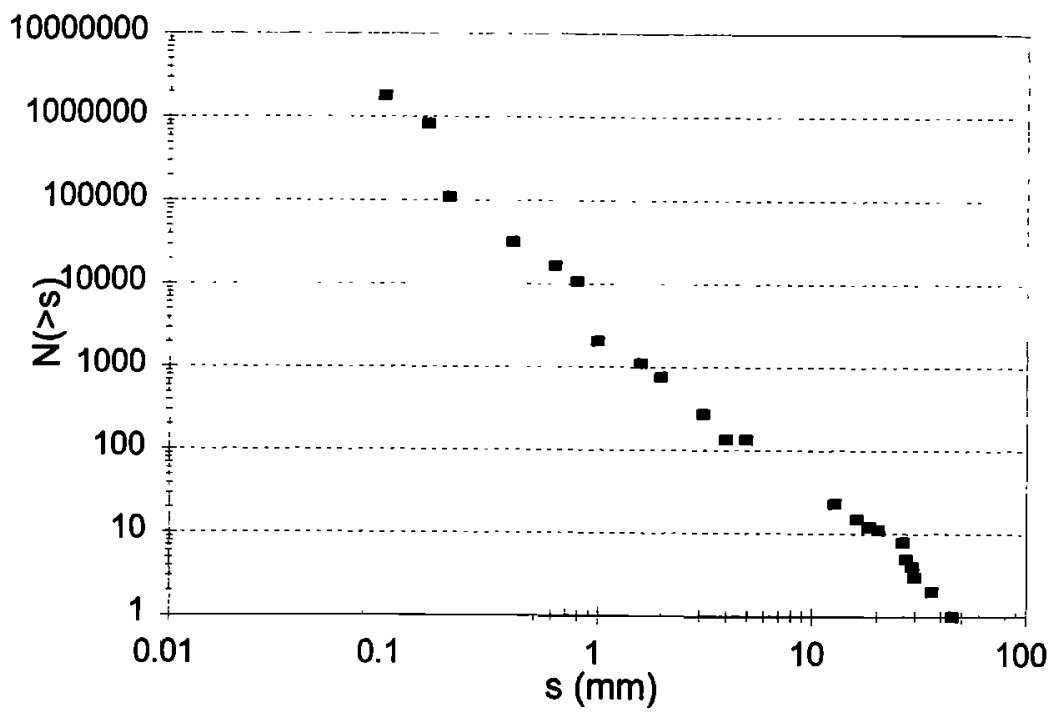

Figure 11. Cumulative distribution of fragment sizes for a sample loaded up to failure $\left(T=-10^{\circ} \mathrm{C} ; \sigma_{1}=3.1 \mathrm{MPa}\right)$. The slope of the diagram gives a "fractal dimension" $D=2.15$ 
structure is not required to produce a fractal fault pattern. The loading history imposed to the ice samples in this study was pretty simple (constant uniaxial compression stress), and yet a fractal organization emerges spontaneously since the onset of tertiary creep. It can therefore be considered as a strong "attractor" of the fracturing process. Note that the influence of the anisotropy of the applied stress field on this organization also vanishes at failure.

The fractal organization of fracturing indicates that scaleinvariant processes of fragmentation take place during tertiary creep, similar to those guesstimated for the fragmentation of rocks [Korvin, 1992]. One can note here that the "fractal dimension" $D$ of the fragments of ice within the fault gouge at failure, determined from the slope of the power law distribution $N(>s) \sim s^{-D}$ on Figure 11 , where $N(>s)$ is the number of fragments of size larger than $s$, is equal to 2.15 , in very good agreement with values of $D$ reported for fragmented granites (between 2.1 and 2.5, [Korvin, 1992]). The simultaneity between the onset of tertiary creep and the emergence of a fractal organization and of isolated fragments strongly suggests that the acceleration of deformation during tertiary creep is due to the cataclasis of a material which becomes granular. Mechanisms such as rolling, crushing of fragments, buckling of slabs, have been proposed to explain the deformation of fault gouges [King and Sammis, 1992], and are probably responsible, at least partially, for the tertiary creep of fractured ice. Note that the fracture networks and fragment shapes within natural fault gouges loaded under shear [Sammis et al., 1987] do not display anisotropy, in agreement with our observations for the latest stages of fracturing of ice.

If all the fractures of the network participate in the fragmentation of the ice, a network with a fractal dimension $D_{0}$ close to 2 in two dimensions, as observed here (and therefore close to 3 in three dimensions), should theoretically results in an exponent $D$ close to 3 [see, e.g., Korvin. 1992], much larger than the observed value of 2.15. This difference could be explained as follows: only a fraction of the fractures observed on thin sections, possibly the more opened, participate in the fragmentation. Unfortunately, the opening of the fractures was impossible to evaluate during this work. The network of "significant" fractures would be less dense than the entire network, with possibly its own multifractal structure, different from the structure of the total network.

A fractal set implies a scale invariance and the appearance of identical features at different scales. In real world, this scale invariance is generally bounded [Lei et al., 1993; Grasso and Bachelery, 1995]. In the present case, the lower bound $l_{c}$, initially related to the microstructure of the material, decreased during the fracturing process and became undetectable at failure, i.e., below the resolution limit of $0.1 \mathrm{~mm}$. Our analysis did not reveal any upper bound for scale invariance, up to a scale of about $50 \mathrm{~mm}$ (see Figure 11). One can wonder over which scale range this fractal organization of fracturing holds. Matsushita [1985], cited by Korvin [1992], reported a power law distribution for the sizes of pieces of drift sea ice in the Okhotsk Sea with a "fractal dimension" $D=2.16$, in remarkable agreement with the value of $D$ obtained at failure in this study $(D=2.15)$. This strongly suggests the fractal organization of fracturing of ice to be sustained over a much larger scale range than the one explored during laboratory experiments. This is also in agreement with the observation of very similar cracking features (and possibly similar cracking mechanisms), such as wing cracks, at the laboratory scale and in the field [Schulson, 1997]. Columnar sea ice [Matsushita, 1985] and granular freshwater ice (this work) have very different microstructures. Yet, they present very similar fragmentation patterns. This confirm that a fractal organization is a strong attractor of the fracturing/fragmentation process.

Finally, as already stressed by Davy et al. [1990], an important consequence of the fractal organization of fracturing of ice is that the homogenization procedures developed to study the behavior of damaged materials are useless during tertiary creep. These procedures require the definition of an elementary volume representative of the behavior of the full body. Because of the fractal geometry of the fracture networks, without characteristic internal scale, such an elementary volume cannot be defined. Similarly, damage mechanics, often applied to ice under compression [see, e.g., Xiao and Jordaan, 1996], and which suppose a uniform distribution of damage, is not valid for tertiary creep and failure. Instead, renormalization approaches [Allègre et al., 1982; Turcotte, 1992] would be more appropriate but need to be refined and completed before to be useable to predict field-scale data from laboratory experiments.

Acknowledgments. We would like to thank E.M. Schulson, J.R. Grasso and $F$. Lahaie for valuable discussions and comments, as well as $\mathrm{O}$. Gamot N. Hotellier, and O. Plé for technical assistance. Comments from two referees helped us to greatly improve the clarity of the manuscript. This work was supported by the GdR Geomécanique des Roches Profondes. LGGE is a laboratory associated with Université J. Fourier, Grenoble.

\section{References}

Allègre, C.J., J.L. Le Mouel, and A. Provost, Scaling rules in rock fracture and possible implications for earthquake predictions, Nature, 297,47 49, 1982.

Ashby, M.F., and S.D. Hallam, The failure of brittle solids containing smal cracks under compressive stress states, Acta Metall., 34, 497-510, 1986

Barton, C.C., and E. Larsen, Fractal geometry of two-dimensional fracture networks at Yucca Mountain, southwestern Nevada, in Proceedings of International Symposium on Fundamentals of Rock Joints, edited by $O$ Stephanson, pp77-84, Centek, Björkliden, Sweden, 1985.

Cole, D.M., Effect of grain size on the internal fracturing of polycrystalline ice, CRREL Rep. 86-5, Cold Reg. Res. and Eng. Lab., Hanover, N.H., 1986

Cowie, P.A., D. Sornette, and C. Vanneste, Multifractal scaling properties of a growing fault population, Geophys. J. Int., 122, 457-469, 1995.

Davy, P., A. Sornette, and D. Sornette, Some consequences of a proposed fractal nature of continental faulting, Nature, 348, 56-58, 1990.

Duval, P., M.F. Ashby, and I. Anderman, Rate-controlling processes in the creep of polycrystalline ice, J. Phys. Chem., 87, 4066-4074, 1983.

Frost, H.J., Mechanisms of crack nucleation in ice, paper presented at Joint Applied Mechanics and Materials Summer Conference AMD-MD '95, Univ. of Calif., Los Angeles, June 28-30, 1995.

Grasso, J.R., and P. Bachelery, Hierarchical organization as a diagnostic approach to volcano mechanics: validation on Piton de la Fournaise, Geophys. Res. Lett., 22, 2897-2900, 1995.

Hallam, S.D., P. Duval, and M.F. Ashby, A study of cracks in polycrystalline ice under uniaxial compression, J. Phys., 48, 303-311, 1987.

Hentschel, H.G.E., and I. Procaccia, The infinite number of generalized dimensions of fractals and strange attractors, Physica $D, 8,435-444$, 1983.

Hirata, T., T. Satoh, and K. Ito, Fractal structure of spatial distribution of microfracturing in rock, Geophys. J. R. Astron. Soc., 90, 369-374, 1987.

King, G.C.P., and C.G. Sammis, The mechanisms of finite brittle strain, Pure Appl. Geophys., 138, 611-640, 1992.

Korvin, G., Fractal Models in the Earth Sciences, Elsevier, New York, 1992.

Kusunose, K., X. Lei, O. Nishizawa, and T. Satoh, Effect of grain size on fractal structure of acoustic emission hypocenter distribution in granitic rock, Phys. Earth Planet. Inter., 67, 194-199, 1991.

Lei, X., O. Nishizawa, and K. Kusunose, Band-limited heterogeneous fractal structure of earthquakes and acoustic emission events, Geophys. J. Int., 115, 79-84, 1993.

Main, I., Statistical physics, seismogenesis, and seismic hazard, Rev. Geophys., 34, 433-462, 1996

Matsushita, M., Fractal viewpoint of fracture and accretion, J. Phys. Soc. Jpn., 54, 857-860, 1985.

Ouillon, G., and D. Somette, Unbiased multifractal analysis: application to fault patterns, Geophys. Res. Lett., 23, 3409-3412, 1996. 
Ouillon, G., C. Castaing, and D. Sornette, Hierarchical geometry of faulting, J. Geophys. Res., 101, 5477-5487, 1996a.

Ouillon, G., D. Sornette, A. Genter, and C. Castaing, The imaginary part of rock jointing, J. Phys. I, 6, 1127-1139, 1996b.

Pickering, G., J.M. Bull, and D.J. Sanderson, Sampling power law distributions, Tectonophysics, 248, 1-20, 1995.

Plé, O., J. Meyssonnier and J. Weiss, Microcrack nucleation in different kinds of artificial ice during uniaxial compression creep experiments, in Micromechanics of Plasticity and Damage of Multiphase Materials, edited by A. Pineau and A. Zaoui, pp223-230, Kluwer Acad., Norwell, Mass., 1996.

Sammis, C.G., G.C.P. King and R. Biegel, The kinematics of gouge deformation, Pure Appl. Geophys., 125, 777-812, 1987.

Schulson, E.M., The brittle compressive fracture of ice, Acta Metall. Mater., 38, 1963-1976, 1990.

Schulson, E.M., The brittle failure of ice under compression, J. Phys. Chem. B, 101, 6254-6258, 1997.

Schulson, E.M., and O.Y. Nickolayev, Failure of columnar saline ice under biaxial compression: Failure envelopes and the brittle-to-ductile transition, J. Geophys. Res., 100, 22383-22400, 1995.

Turcotte, D.L., Fractals and fragmentation, $J$ Geophys. Res., 91, 19211926, 1986.

Turcotte, D.L., Fractals and Chaos in Geology and Geophysics, Cambridge Univ. Press, New York, 1992.
Underwood, E.E., Quantitative Stereology, Addison-Wesley, Reading, Mass., 1970.

Velde, B., D. Moore, A. Badri, and B. Ledesert, Fractal and length analysis of fractures during brittle to ductile changes, $J$. Geophys. Res., 98, 11935-11940, 1993.

Weiss, J., and E.M. Schulson, The failure of fresh-water granular ice under multiaxial compressive loading, Acta. Metall Mater., 43, 2303-2315, 1995.

Weiss, J., E.M. Schulson, and H.J. Frost, The nucleation of microcracks in ice cubes compressed equally on all boundaries, Philos. Mag. A, 73, 1385-1400, 1996.

Xiao, J., and I.J. Jordaan, Application of damage mechanics to ice failure in compression, Cold Reg. Sci. Techol., 24, 305-322, 1996.

M. Gay and J. Weiss, LGGE, Domaine Universitaire, 54 rue Molière, B.P. 96, 38402 Saint-Martin-D'Hères cedex, France. (e-mail: weiss@glaciog.ujf-frenoble.fr)

(Received November 12, 1997; revised April 8, 1998; accepted May 19, 1998.) 